Int. J. Morphol.,

32(1):29-31, 2014.

\title{
An Anomalous Pattern of Superficial Branch of Radial Nerve - A Cadaveric Case Report
}

\author{
Patrón Anómalo del Ramo Superficial del Nervio Radial - Reporte de Caso en un Cadaver
}

\author{
Nurul Huda Mohd Nor*; Aye Aye San* \& Fauziah Othman*
}

NURUL-HUDA, M. N.; SAN, A. A. \& FAUZIAH, O. An Anomalous pattern of superficial branch of radial nerve - A cadaveric case report. Int. J. Morphol., 32(1):29-31, 2014.

SUMMARY: In the present case study, there is an anomalous pattern of superficial branch of radial nerve (SBRN) that can be recognized as an anatomical variant of the left upper limb of a 60 years old donated embalmed male cadaver in the Department of Human Anatomy, Universiti Putra Malaysia, in which the superficial branch of radial nerve supplies the extensor carpi radialis longus and extensor carpi radialis brevis muscle. The superficial branch of radial nerve gave off branch to supply the proximal fusion part of extensor carpi radialis longus and extensor carpi radialis brevis muscles immediately after bifurcation of the radial nerve into the superficial branch of radial nerve and deep branch of radial nerve. This variation is very important to the surgeon as the presence of the variant will make them more careful in dealing with nerve entrapment surgery, reconstructive surgery and in the pain management services, the variation giving indications for treatment.

KEY WORDS: Anatomical variant; Superficial branch of radial nerve; Extensor carpi radialis longus; Extensor carpi radialis brevis.

\section{INTRODUCTION}

The radial nerve arises from the posterior cord of the brachial plexus. It passes by the posterior wall of the axilla, below the tendon of latissimus dorsi, goes downwards between the long and medial heads of triceps. It twists across the humerus and is lying on the radial groove of the bone. It gives off branches to supply medial head and long head of triceps muscle as well as a cutaneous branch which supplies the skin along the posterior surface of the upper arm. The nerve then pierces the lateral intermuscular septum at the point of one- third from deltoid tuberosity to the lateral epicondyle (Sinnatamby, 2006). The nerve then divides into superficial branch of radial nerve and deep branch of radial nerve at the level of the lateral epicondyle. The deep branch of radial nerve and also known as posterior interosseous nerve is the nerve of extensor compartment of the forearm as it twists around the radius then dips into the interosseous membrane and ends at the wrist joint. Whilst the deep branch of radial nerve which is a purely motor nerve, the superficial branch of radial nerve is a purely sensory nerve which travels underneath the brachioradialis muscle, radiates to subcutaneous position by passing between the brachiradialis muscle tendon and extensor carpi radialis longus tendon piercing the deep forearm fascia (Tryfonidis et al., 2004).
The variation of the radial nerve particularly the superficial branch of radial nerve had been reported before (Tryfonidis et al.). However, this present report demonstrates that the superficial branch of radial nerve supplied both the extensor carpi radialis longus and extensor carpi radialis brevis. Anatomical variations of peripheral nerves will be appreciated by medical personnel, especially by orthopedic surgeons, neurophysicians, plastic surgeons, physiotherapists and radiologists (Yogesh et al., 2011) Such knowledge is valuable in term of nerve grafting, donor for sensate flap and neurophysiologic evaluation to diagnose peripheral neuropathies(Jeng \& Wei, 1998).

\section{CASE REPORT}

During routine dissection class for upper limb at the Department of Human Anatomy, Universiti Putra Malaysia, an anomalous pattern of radial nerve was discovered, which displayed variation of the distribution of superficial radial nerve of left upper limb of a 60-year-old donated embalmed male cadaver. The radial nerve was exposed after deflexed 
brachioradialis muscle. The radial nerve bifurcated into deep and superficial branches at the lateral epicondyle. During the observation, following the bifurcation, we noted the superficial branch of radial nerve gave off branch to supply the proximal fusion fleshy part of the extensor carpi radialis longus and extensor carpi radialis brevis muscle. The superficial branch of radial nerve then proceeded to pierce the deep forearm fascia to become subcutaneous at the back of the wrist. Distal to this point, it bifurcated to medial and lateral branches to supply the hand. The dissection was continued with the deep branch of radial nerve, showing the same as describe in standard text books as in the nerve that pierces the tendon of the supinator muscle, it enters the posterior compartment of forearm and continues as posterior interosseous nerve.

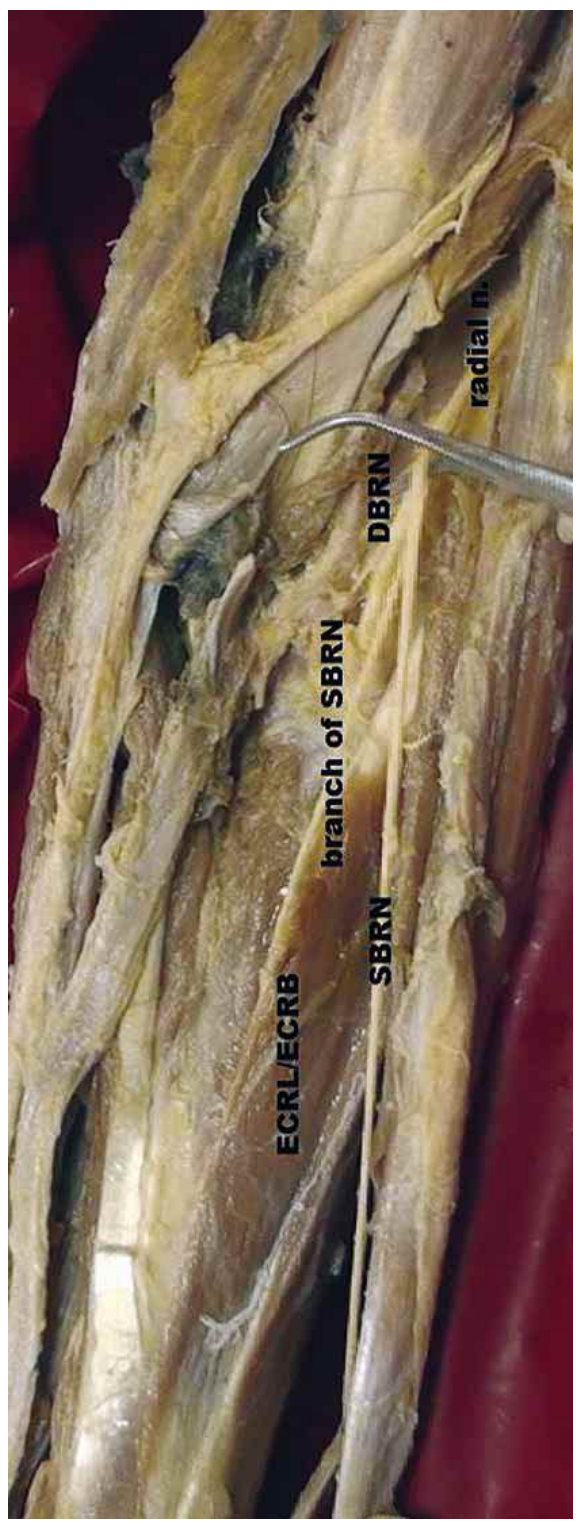

journals (Linell, 1921; Marathe et al., 2010; Tryfonidis et al.). Tryfonidis et al., reported the variation of the course of superficial branch of radial nerve that the superficial branch of radial nerve was piercing the brachioradialis muscle tendon to become subcutaneous. Linell reported a fusion of the brachioradial muscle tendon and the extensor carpi radialis longus tendon with the superficial branch of radial nerve piercing the fused tendon. Moreover, a nearly similar variation as stated in this present case study was noticed many years ago. The incidence of the superficial branch of radial nerve supply to ECRB has been reported as 56\%, 48\% and 25\% respectively (al-Qattan, 1996; Branovacki et al., 1998; Salsbury, 1938). However, the present case variation has previously never been reported in the literature. This is the first document reporting on a variation that involved both extensor carpi radialis longus and brevis. Nevertheless, these variations were not stated in the standard text books as a reference for students and surgeon.

The clinical significant of this variation may be observed in the traumatic transection of the distal forearm. As the superficial branch of radial nerve is purely sensory nerve, the traumatic injury may result in a painful neuroma (alQattan). In the case of superficial branch of radial nerve injury may also lead to pain during extension of the wrist and slight weakness of the wrist joint extension due to involvement of the nerve supply of the extensor carpi radialis longus and extensor carpi radialis brevis (Sawant et al., 2012). The present report of the additional branch of the superficial branch of radial nerve in extensor carpi radialis longus and extensor carpi radialis brevis can be of benefit for the hand surgeon as it can be used as donor site for a sensate flap during reconstructive surgery (Yan et al., 2012). The awareness of the variation of nerve distribution especially in superficial branch of radial nerve in clinical setting should be prioritized mainly by physiotherapists and anaesthesiologists as pain managing therapists, as well as surgeons dealing with nerve entrapment or compressive neuropathies and reconstructive surgery.

Fig. 1. Photograph of the nerve to the ECRL and ECRB arising from the superficial branch of radial nerve. ECRL= Extensor Carpi Radialis Longus muscle; ECRB= Extensor Carpi Radialis Brevis muscle; $\mathrm{SBRN}=$ Superficial branch of Radial Nerve; DBRN= deep branch of Radial Nerve. 
NURUL-HUDA, M. N.; SAN, A. A. \& FAUZIAH, O. Patrón anómalo del ramo superficial del nervio radial - Reporte de caso en un cadaver. Int. J. Morphol., 32(1):29-31, 2014.

RESUMEN: En el presente estudio se observó un caso de un patrón anómalo del ramo superficial del nervio radial (RSNR) reconocido como una variante anatómica del miembro superior izquierdo en un cadáver de sexo masculino de 60 años perteneciente al Departamento de Anatomía Humana de la Universidad Putra, Malasia. En este caso el ramo superficial del nervio radial inervaba a los músculos extensores radial largo y corto del carpo. El ramo superficial del nervio radial otorgaba un ramo a nivel del origen fusionado de los músculos extensores radiales del carpo, inmediatamente después de la división en ramos superficial y profundo del nervio radial. Esta variación es de importancia para el cirujano debido a que requiere un mayor cuidado en el tratamiento quirúrgico de atrapamiento del nervio o cirugía reconstructiva para el manejo del dolor.

PALABRAS CLAVE: Variante anatomica; Rama superficial del nervio radial; Extensor carpi radialis longus; Extensor carpi radialis brevis.

\section{REFERENCES}

al-Qattan, M. M. The nerve supply to extensor carpi radialis brevis. J. Anat., 188(Pt. 1):249-50, 1996.

Branovacki, G.; Hanson, M.; Cash, R. \& Gonzalez, M. The innervation pattern of the radial nerve at the elbow and in the forearm. J. Hand Surg. Br., 23(2):167-9, 1998.

Jeng, S. F. \& Wei, F. C. The distally based forearm island flap in hand reconstruction. Plast. Reconstr. Surg., 102(2):400-6, 1998.

Linell, E. A. The Distribution of Nerves in the Upper Limb, with reference to Variabilities and their Clinical Significance. $J$. Anat., 55(Pt. 2-3):79-112, 1921.

Marathe, R. R.; Mankar, S. R.; Joshi, M. \& Sontakke, Y.A. Communication between radial nerve and medial cutaneous nerve of forearm. J. Neurosci. Rural Pract., 1(1):49-50, 2010.

Salsbury, C. R. The nerve to the extensor carpi radialis brevis. $B r$. J. Surg., 26(101):95-7, 1938.

Sawant, S. P.; Shaikh, S. T.; Lele, S. D.; Rizvi, S.; Menon, S. R. \& Uma, R. Extensor Carpi Radialis Brevis Supplied by The Superficial Branch of Radial Nerve - A Cadaveric Case Report. Int. J. Curr. Res. Rev., 4(24):100-4, 2012.

Sinnatamby, C. S. Last's Anatomy: Regional and Applied. $11^{\text {th }}$ ed. London, Churchill Livingstone, 2006. pp.58-100.

Tryfonidis, M.; Jass, G. K.; Charalambous, C. P. \& Jacob, S. Superficial branch of the radial nerve piercing the brachioradialis tendon to become subcutaneous: An anatomical variation with clinical relevance. Hand Surg., 9(2):191-5, 2004.

Yan, H.; Gao, W.; Zhang, F.; Li, Z.; Chen, X. \& Fan, C. A comparative study of finger pulp reconstruction using arterialised venous sensate flap and insensate flap from forearm. J. Plast. Reconstr. Aesthet. Surg., 65(9):1220-6, 2012.
Yogesh, A.; Marathe, R. \& Pandit, S. Musculocutaneous nerve substituting for the distal part of radial nerve: A case report and its embryological basis. J. Neurosci. Rural Pract., 2(1):74$6,2011$.

Correspondence to:

Prof. Dr. Fauziah Othman

Department of Human Anatomy

Faculty of Medicine and Health Sciences

Universiti Putra Malaysia, 43400 UPM Serdang

Selangor

MALAYSIA

Email: fauziah@upm.edu.my

Received: 04-09-2013

Accepted: 19-11-2013 